\title{
Workplace information literacy: a bridge to the development of Innovative Work Behaviour
}

Lyndsey Middleton, Communities Analysis Division, The Scottish Government, Edinburgh, UK, and Hazel Hall, Centre for Social Informatics, Edinburgh Napier University, Edinburgh, UK

This article manuscript was accepted for publication by the Journal of Documentation on $26^{\text {th }}$ May 2021; manuscript number JD-03-2021-0065

\section{Abstract}

\section{Purpose}

Organisational culture and leadership, employee skills and aptitudes, access to resources, and training are regularly cited as important determinants of the development of Innovative Work Behaviour (IWB). The purpose of the work reported in this paper was to investigate a further set of possible determinants of the development of IWB: those that are informationrelated.

\section{Design/methodology/approach}

A mixed methods approach was adopted. Quantitative and qualitative data were collected by questionnaire, interview, and focus groups in three large public sector case study organisations in Scotland, Finland, and England.

\section{Findings}

A set of information-related determinants of the development of IWB are evidenced, adding to the list of determinants that are already well documented. Notably workplace information literacy (IL) appears to furnish a bridge between determinants of the development of IWB and workplace learning.

\section{Originality}

That information-related determinants may be valuable to the development of IWB has not previously merited specific consideration, nor been recognised, in the wider IWB literature. The identification of these determinants in this research should encourage researchers and professionals beyond the domain of Information Science to pay serious attention to IL. This 
Middleton, L. \& Hall, H. (2021, in press). Workplace information literacy: a bridge to the development of Innovative Work Behaviour. Journal of Documentation. (Manuscript accepted for publication 26 ${ }^{\text {th }}$ May 2021.)

is particularly important in respect of the role of workplace IL in processes that lead to new knowledge creation and innovation.

\section{Keywords}

information literacy, information sharing, IL, innovation, innovative work behaviour, IWB, workplace information literacy, workplace learning

\section{Introduction}

Innovation has long been regarded as valuable to competitive advantage (e.g. Anderson, de Dreu \& Nijstad, 2004, p. 149) with employees at its heart (e.g. Ellström, 2010; Høyrup, 2010). It thus follows that the collective innovation performance of an organisation is reliant on employee-led innovation. In cases where this can be enhanced, benefits are accrued both by employer and employees, for example in skills development and learning (e.g. Alasoini, 2015).

Recently there have been calls in the Information Science literature for the generation of concrete evidence that ties information literacy (IL) (as a facet of information behaviour) to innovation. This, it is argued, would encourage business professionals and management researchers to pay serious attention to IL (e.g. Cheuk, 2017; Goldstein \& Whitworth, 2017). While these calls have been heeded in some work (e.g. Ahmad, Widén \& Huvila, 2020), with the exception of Middleton, Hall, Muir and Raeside (2019), none considers the part that IL plays in furnishing employees with the capacity to engage with Innovative Work Behaviour (IWB). This is not just an issue in respect of IWB. Widén, Ahmad, Nikou, Ryan and Cruickshank (2021 in press) note that although prior research on workplace IL has generated knowledge on its development and value, its contribution to supporting organisational efficiency or the meeting of organisational goals in general is less well understood.

Organisational culture and leadership, employee skills and aptitudes, access to resources, and training are regularly cited as important determinants of the development of IWB. The aim of the empirical work described in this paper was to investigate a further set of possible 
Middleton, L. \& Hall, H. (2021, in press). Workplace information literacy: a bridge to the development of Innovative Work Behaviour. Journal of Documentation. (Manuscript accepted for publication 26 ${ }^{\text {th }}$ May 2021.)

information-related determinants. The novel contribution of the study - achieved through the application of theory from Information Science - is the identification of the particular importance of workplace IL and information sharing (which features as an element of IL in many IL models) to IWB. Neither of these has previously merited specific consideration in the wider IWB literature. In particular, here it is shown that workplace IL conceived as 'a way of knowing an information landscape' (Lloyd, 2012, p. 772) may serve as a bridge between workplace learning and the development of IWB.

A further contribution of this research is demonstration of the value of a mixed methods approach to explore IL in workplace contexts. The study reported here is one of few on workplace IL that centre on the analysis of both quantitative and qualitative data sets unlike the majority that rely purely on the analysis of qualitative data (Widén et al, 2021 in press).

In the account below, the context for the report of the empirical work is set through the presentation of a literature review on the theme of IWB, and possible links between workplace IL and IWB. This includes a discussion of IL as treated in prior research, with reference to the range of conceptualisations of the term. At one extreme is the 'skills' view, where many (such as academic librarians) advocate that IL is a set of skills that support desirable information behaviours. At the other, researchers (such as Lloyd) forward a 'practice' view, arguing that IL is an information behaviour per se, embedded in practice.

There then follows an explanation of research design and the implementation of three case studies in Scotland, Finland, and England. The main results from the analysis of the quantitative and qualitative data collected by questionnaire, interview, and focus group follow. These findings are then discussed to highlight the unique contribution of this work to research in IWB and IL. 
Middleton, L. \& Hall, H. (2021, in press). Workplace information literacy: a bridge to the development of Innovative Work Behaviour. Journal of Documentation. (Manuscript accepted for publication 26 ${ }^{\text {th }}$ May 2021.)

\section{Literature review}

Prior work on IWB and its determinants has been reported across several domains in the social sciences including Human Resource Management, Management, Organisational Studies, Psychology and Sociology. The review here is concerned first with defining the concept of IWB, identifying its activity stages, and presenting its determinants as related to (1) organisational context and (2) employee skills and aptitudes, and access to resources and training. Extant work on IWB in the Information Science literature is then analysed, drawing attention to the lack of coverage of the topic, despite the possible relevance of informationrelated determinants to the development of IWB.

\subsection{IWB and its determinants: the social science perspective \\ 2.1.1 IWB as a concept}

Drawing on the work of Battistelli, Montani, and Odoardi (2013, p. 27), Janssen (2000, p. 288), de Jong and den Hartog (2010), and West and Farr (1990, pp. 5-7), the deployment of the term 'Innovative work behaviour' (IWB) here refers to the intentional generation of new ideas in the workplace at the level of employee, group or organisation, with the expectation (but not the certainty) that these ideas will be of benefit and be implemented in some way as an innovation, e.g. a new product, service, or mode of operation. A number of activity stages are presented in the published models of IWB, ranging in number from two (e.g. Krause, 2004) to five (e.g. Messman \& Mulder, 2011). Although it is recognised that these stages are not discrete (Botha \& Steyn 2020, p. 6), they provide a framework for theorising IWB (and are deployed as such in the empirical work discussed later in this paper). The most widely cited are those identified by de Jong and den Hartog (2010, pp. 24-25), as summarised in Table I.

\section{Table I: The stages of IWB}

\begin{tabular}{|c|l|}
\hline Stage & Process \\
\hline $\mathbf{1}$ & Recognition of the need for innovation \\
\hline $\mathbf{2}$ & Creation of an idea \\
\hline $\mathbf{3}$ & Championing of, and/or gaining support for, the idea \\
\hline $\mathbf{4}$ & Implementation of the idea \\
\hline
\end{tabular}


Middleton, L. \& Hall, H. (2021, in press). Workplace information literacy: a bridge to the development of Innovative Work Behaviour. Journal of Documentation. (Manuscript accepted for publication 26 ${ }^{\text {th }}$ May 2021.)

IWB is important to organisations because it plays a mediating role in the relationship between the organisational climate for innovation and organisational performance (Shanker, Bhanugopan, Heijden, Van Der \& Farrell, 2017). Advantage is taken of 'individuals operating "close to the ground" [as] an invaluable source of information on trends in the market, changes in competition dynamics, opportunities for operational improvements and other important insights' (Botha \& Steyn, 2020, p. 1). Employees exhibit IWB in their interactions with materials, customers, and users as they acquire information and experience-based knowledge (Høyrup, 2010, p.143).

A further significant aspect of IWB is its links to learning throughout all the stages summarised above. Since failure is a possible outcome of efforts to develop an 'innovation' through the stages of IWB, lessons from unsuccessful applications are valued as 'innovative learning' (Høyrup, 2010, p.152). Gained through experiences encountered at work, innovative learning may be conceived as a type of workplace learning on a par with the acquisition of employment and organisational specific skills and knowledge through formal training programmes and informal interactions.

\subsubsection{IWB determinants}

Levels of IWB within organisations, as well as associated learning, are underpinned and influenced by a number of determinants. The most commonly cited are found in a body of extant literature on IWB that stretches back to seminal work by Scott and Bruce (1994) (BosNehles Renkema \& Janssen, 2017, p. 1230; Botha \& Steyn, 2020, p. 3). They fall into two categories. First are determinants that relate to organisational context, such as organisational culture and leadership. Second are determinants concerned with employees such as their skills and the resources to which they have access. The nature of these determinants is elaborated below with reference to a range of papers that covers both reports of empirical studies focussed on IWB (e.g. Battistelli et al, 2013), and reviews of the IWB literature (e.g. Bos-Nehles et al, 2017).

An organisational culture conducive to IWB values communication across a connected workforce (e.g. Martins \& Terblanche, 2003; Muchiri, McMurray, Nkhoma \& Pham, 2020) in which knowledge is shared (e.g. Hu \& Zhao, 2016; Kmieciak, 2020; Radaeilli, Lettieri, Mura, 
Middleton, L. \& Hall, H. (2021, in press). Workplace information literacy: a bridge to the development of Innovative Work Behaviour. Journal of Documentation. (Manuscript accepted for publication 26 ${ }^{\text {th }}$ May 2021.)

\& Spiller, 2014). The workforce is supported by the promotion of a compatible strategy (e.g. Rude, 2014, p. 130-131) that encourages employees to embrace innovation and change (e.g. Åmo \& Kolvereid, 2005), with enhanced employee innovation and performance as its desired and anticipated outcomes (e.g. Muchiri et al, 2020, p. 34; Prajogo, 2016, p.247).

Similarly, leadership is regarded key to growing a culture that encourages IWB (e.g. Botha \& Steyn, 2020, p.2; Muchiri et al, 2020, p. 34), especially in respect of idea generation and application (stages 1 and 2). For IWB to flourish within an organisation, leaders should be skilled communicators, sharing ideas and feedback with their employees (e.g. Bos-Nehles 2017, p. 1237). Leadership roles conducive to promoting IWB comprise empowering employees to innovate (e.g. Jung, Chow \& Wu, 2003; Fernandez \& Moldogaziev, 2013), allowing them freedom to execute their work roles independently (e.g. Janssen, 2005; Jung et al., 2003; Ramamoorthy, Flood, Slattery \& Sardessai, 2006), supporting them through difficult times of change (Martins \& Martins, 2002; Sarros, Cooper \& Santora, 2008), and encouraging creativity and the development of innovation-related skills through autonomous working (e.g. Bos-Nehles et al, 2017, p. 1234; Mumford, Scott, Gaddis \& Strange, 2002, p. 737). At the same time, leaders need to provide resources and tools that provide a platform for IWB to be developed and enacted (e.g. Andersson, 2006, p. 677; Botha \& Steyn, 2020, p. 2; Ferincz \& Hortoványi, 2014, p. 848; Hamel, 2007; Oksanen \& Ståhle, 2013; Ravenscroft, Schmidt, Cook \& Bradley, 2012, p. 237).

At the level of the individual, a range of employee skills and aptitudes have been identified as determinants of IWB. These range from competences such as problem-solving (Billett, 2012; Ellström 2010; Eriksson, Qin \& Wang, 2014) to the personal dispositions of employees (e.g. Muchiri, McMurray, Nkhoma \& Pham, 2020, p. 34), such as their willingness to participate in learning and innovation activities (Gustavsson, 2009), and their attitudes to job stress, competition between colleagues, and interpersonal conflicts (Botha \& Steyn, 2020 , p. 2). In their review of published research on personality traits and IWB, for example, Woods, Mustafa, Anderson and Sayer (2018) identified that openness and conscientiousness are readily identified as predictors of IWB. Training and development also plays a part in the development of IWB in employees (e.g. Bos-Nehles et al, 2017, p. 1232; 
Middleton, L. \& Hall, H. (2021, in press). Workplace information literacy: a bridge to the development of Innovative Work Behaviour. Journal of Documentation. (Manuscript accepted for publication 26 ${ }^{\text {th }}$ May 2021.)

Knol \& van Linge, 2009; Pratoom \& Savatsomboon, 2010), especially when it leads to the acquisition of skills in innovative learning (Lundkvist \& Gustavsson, 2018), and provides opportunities to implement skills developed beyond the training context (Clarke, 2005, p. 190). In addition, Messman and Mulder (2011) consider skills in reflection important enough to merit a fifth stage in their model of IWB (further to the four other stages that match with the commonly cited articulation presented above, and as adopted for this study). Here 'reflection encompasses assessing the progress of innovation development, evaluating activities and outcomes based on criteria for success, examining one's personal advancement during innovation development, and improving action strategies for future situations' (p. 46).

While the determinants of IWB cited above are most frequently discussed in terms of their positive influence on IWB, several can exert both a positive and negative influence. This depends on moderating factors such as occupational group or geography. For example, BosNehles et al (2017) noted in their literature review that the value of financial rewards, job complexity, job demands, job security, job design to the support of IWB vary from study to study (p. 1233-1237). For instance, they cite Noefer, Stegmaier, Molter and Sonntag (2009), who found that time pressure has a negative impact on stage 2 of IWB (creation of an idea) but a positive one on stage 4 (implementation) (p. 1237). They also highlight De Spiegelaere, van Guys and van Hootegem's (2012) finding that white collar workers have a greater need for stimulating and challenging jobs to motivate them to engage in IWB than do blue collar workers (p. 1236). Similarly, Botha and Steyn $(2020$, p. 2 ) note that many studies of IWB that cover psychological contract breach (i.e. employee perception that the employer has failed to deliver on its promises and obligations in exchange for labour) show that this is negatively correlated with IWB, whereas others point to the opposite conclusion.

The determinants of IWB as discussed above are drawn from numerous publications in domains such as Human Resource Management, Management, Organisational Studies, Psychology, and Sociology. As such, the theories have been forwarded to explain their nature emanate from the social sciences for application in organisational and industrial settings. From Psychology, these include Cognitive evaluation theory (Deci \& Ryan, 1985), 
Middleton, L. \& Hall, H. (2021, in press). Workplace information literacy: a bridge to the development of Innovative Work Behaviour. Journal of Documentation. (Manuscript accepted for publication 26 ${ }^{\text {th }}$ May 2021.)

Job demands resources theory (Bakker \& Demerouti, 2007), Self determination theory (Gagné \& Deci, 2005), and Trait activation theory (Lievens, Chasteen, Day, \& Christiansen, 2006). From Sociology, Social exchange theory (Blau, 1964) is invoked. (For a more detailed assessment of the contribution of these theories in the understanding of determinants of IWB see the summary by Bos-Nehles et al (2017, p. 1238)).

\subsection{Innovation, IWB and Information Science}

There exists a seam of published research in Information Science on the broad topic of innovation. Examples of innovation-related themes considered in this work include: the development of creativity skills (e.g. Auernhammer \& Hall, 2013; Lavranos, Kostagiolas, Martzoukou \& Papadatos, 2015); fostering innovation in information services (e.g. Koloniari, Vraimaki \& Fassoulis, 2018); the relationships between knowledge acquisition, absorptive capacity and innovation capability (Liao, Wu, Hu \& Tsui, 2010); and information seeking behaviour as a predictor of innovation capability (Popoola \& Fagbola, 2014).

However, in contrast with the researchers in the domains cited above, members of the research community whose focus is the organisational use of information have paid little direct attention to the specific concept of IWB, and - to date - no attempts have been made to explain IWB using theory generated in Information Science. Indeed, only two papers on the topic have been published in Information Science titles since 2015. The first paper is 'Knowledge-sharing determinants, behaviors, and innovative work behaviors: an integrated theoretical view and empirical examination' (Akhavan, Mahdi Hosseini, Abbasi \& Nateghi, 2015). While this paper's title is indicative of a detailed account of the relationship between knowledge sharing and IWB, IWB is not a core focus of the work reported. Rather, IWB is one of fourteen constructs analysed in the research, and the main finding of relevance to IWB - that knowledge sharing behaviours 'play an important role in development of innovative work behaviors through getting access to others' knowledge and experiences' ( $p$. $577)$ - is not elaborated. The second paper is a report of preliminary research findings from the empirical work that is the focus of this article (Middleton et al, 2019). 
Middleton, L. \& Hall, H. (2021, in press). Workplace information literacy: a bridge to the development of Innovative Work Behaviour. Journal of Documentation. (Manuscript accepted for publication 26 ${ }^{\text {th }}$ May 2021.)

These observations highlight a gap in knowledge on information behaviours at work. This gap is significant given the links between IWB, information, and workplace learning as noted above. Of particular interest is the more specific topic of IL because IL (in general) has been proposed as a driver of 'informed learning' i.e. learning to use information to learn (Somerville \& Bruce, 2017). In addition, workplace IL is also associated with knowledge creation and innovation (Lloyd, 2011, p. 292; Lloyd 2012).

This raises the question as to whether or not the development of IWB be supported by workplace IL. If so, then IL should be considered a determinant of the development of IWB alongside the others that are already widely recognised. In recently published research on workplace IL and innovation by Ahmad et al (2020), it has been indicated that this may indeed be the case. Here, without any direct reference to IWB, a positive link between workplace IL and innovation in small and medium-sized enterprises (SMEs) has been identified. In addition, although the authors do not cite IWB in this work, the processes described in their paper may be mapped to IWB stages e.g. 'opportunity recognition' aligns with stage 1 of IWB (recognition of the need for innovation).

In any discussion of workplace IL it is important to acknowledge that the term is interpreted in different ways across the Information Science literature (Williams, Cooper \& Wavell., 2014) and a single accepted definition is not available (Widén et al, 2021 in press). This divergence of opinion reflects a general problem with the 'parent' term, as noted by Todd (2017). He points out that 'the whole area of [IL] is immersed in a plethora of terminologies, definitions, [and] descriptions' (p. 122), and also bewails the hundreds of IL models (p. 128). In spite of this, two broad conceptualisations of IL can be identified. These are both evident in the use of the more specific term 'workplace IL'. The first conceptualisation of IL is rooted in its earliest definition (Zurkowski, 1974). Here IL is considered as a set of information skills to be acquired by individuals. They learn these skills to become information literate, often with the support of information professionals. This understanding is reflected in the high interest of academic librarians in IL, and the discussion of standards for IL amongst professional groups in Library and Information Science. 
Middleton, L. \& Hall, H. (2021, in press). Workplace information literacy: a bridge to the development of Innovative Work Behaviour. Journal of Documentation. (Manuscript accepted for publication 26 ${ }^{\text {th }}$ May 2021.)

Following this, workplace IL may be regarded as a set of employability skills that supports individuals in finding and making judgements about information, then preparing it for its intended audience, or 'a set of abilities for employees to interact with information when the need to address any business issues or problems at work' (Cheuk, 2008). This narrow definition is an extension of the one commonly deployed in educational settings: it shares a focus on the personal acquisition and application of information skills for handling published information sources. This adaptation, however, does not pay heed to the different contexts of educational and work environments. For example, it fails to take into account that employees (unlike students) undertake their work (and in many cases their learning) collectively as a joint enterprise in the same physical space (or at least the same organisational space, if not located together). In addition, it fails to recognise that workers operate in a wide information ecology that values a variety of internal information sources, not least other people. Furthermore, it does not communicate a sense of workplace learning, nor any link between workplace IL and the meeting of organisational goals. Widén, et al (2021 in press) also note that workplace environments are 'faster paced and less predictable' than education settings. For these reasons, several Information Science researchers argue for a shift in focus from the individual to the social context to consider situated (rather than generic) skills when examining IL (e.g. Cruickshank, Hall \& Ryan, 2020; Goldstein \& Whitworth 2017; Forster, 2017; Olsson, 2014; Webber \& Johnston, 2017).

Prominent amongst these, and a strong critic of the limited 'skills-only' view of IL (both when considering the concept in general and in its application to the workplace), is Lloyd (e.g. 2011, 2012, 2017). Taking a socio-cultural perspective and with reference to Practice Theory, Lloyd (2012) argues for a 'people-in-practice' perspective of IL as 'a way of knowing an information landscape' (p. 772). Here IL belongs to the social site in which it is enacted, rather than owned by any individual (Lloyd, 2012, p. 775). It is 'the outcome of co-location and co-participation, where people shape and inform their practices (including information literacy practice) and operationalise information skills, in agreed ways' (p. 780). This perspective is summarised in Lloyd's Theory of IL (2017, p. 94): 'Information literacy is a practice that is enacted in a social setting. It is composed of a suite of activities and skills 
Middleton, L. \& Hall, H. (2021, in press). Workplace information literacy: a bridge to the development of Innovative Work Behaviour. Journal of Documentation. (Manuscript accepted for publication 26 ${ }^{\text {th }}$ May 2021.)

that reference structured and embodied knowledges and ways of knowing relevant to the context. Information literacy is a way of knowing' (Lloyd's emphasis).

Lloyd has conducted a significant amount of research with workers across a range of employment settings. In the resultant body of literature she has explored: the development and manifestation of IL in the workplace, with reference to social conditions; the functions of IL and its value to workers (e.g. for the interpretation of information environments, to connect people to information and knowledge); and the outcomes of IL in employment settings. On the basis of these detailed analyses, she rejects the notion that workplace IL is merely an assemblage of employability skills for information handling - as might be understood from the skills-based definition noted above. Rather, workplace IL comprises socially enacted, collaborative, context-dependent, embedded, critical work practice that is executed by co-located and co-participating workers using information from internal and external sources. This drives learning, knowledge creation, and - crucially - innovation (Lloyd, 2011, p. 292; Lloyd 2012).

\subsection{IWB and workplace IL: an opportunity to make a contribution}

It has been argued that discussions of the determinants of IWB are principally found in domains such as Human Resource Management, Management, Organisational Studies, Psychology, and Sociology. Although there is reference in this extant literature of the role of knowledge sharing in the development of IWB, here no attempts have been made to analyse in depth information behaviours (in general) that underpin such practice. Meanwhile, despite evident interest in innovation in general, the research community that focuses on the organisational use of information has not paid direct attention to information behaviours that contribute to the skills and activities that underpin the deliberate generation of new ideas in the workplace, i.e. to IWB.

Since workplace IL (as an information behaviour, as noted above) contributes to learning, knowledge creation, and innovation, this raises the question of whether or not workplace IL influences the development of IWB and - if so - its relative importance when compared 
Middleton, L. \& Hall, H. (2021, in press). Workplace information literacy: a bridge to the development of Innovative Work Behaviour. Journal of Documentation. (Manuscript accepted for publication 26 ${ }^{\text {th }}$ May 2021.)

with the well-established determinants as outlined above. In addressing this point, the empirical study reported in this paper responds to calls to enlarge the evidence base on the value of IL amongst employees (e.g. Cheuk, 2017). It also extends earlier work that ties IL specifically to the theme of innovation (e.g. Ahmad et al, 2020).

\section{Methodology}

The empirical work reported in this paper is concerned with a detailed exploration of the determinants of IWB that took into account workplace IL as a possible relevant influencing factor. The findings derive from a multi-methods case study undertaken over a period of 20 months in 2017 and 2018. Qualitative and quantitative data were collected by interview and questionnaire from employees working at different levels in three public sector organisations: (1) a Scottish university, (2) a Finnish university, and (3) an English National Health Service (NHS) Trust. In addition, focus groups were held at the Scottish case study. Each data collection tool was piloted prior to implementation.

This approach was seen to have several advantages. For example, the use of case studies allowed for the study of complex phenomena (determinants of IWB) in a real-life context (three public sector organisations); the diversity in the pool of participants facilitated the collection of multiple perspectives; the gathering of quantitative data led to the identification of the factors, with the qualitative elements providing an opportunity for the results of the quantitative phase to be explored further for their 'meaning' and to surface the relationships between factors; the adoption of mixed methods offered greater opportunities for triangulation of results than would an approach that deployed just one set of methods.

The case study organisations were selected on the basis of known strong commitment to innovation. In the case of the Scottish university, its strategy makes public that innovation is at the heart of its values, and key to its ambition for continuous improvement throughout its operations. The Scottish university also aims to support employee-led innovation by 
Middleton, L. \& Hall, H. (2021, in press). Workplace information literacy: a bridge to the development of Innovative Work Behaviour. Journal of Documentation. (Manuscript accepted for publication 26 ${ }^{\text {th }}$ May 2021.)

providing multiple opportunities for the sharing of resources and exchange of knowledge across the workforce. The strategy of the Finnish university is similar to that of the Scottish university in terms of encouraging collaboration amongst employees. However, it differs in its primary focus on employee skills development. Like the other two case study organisations, the NHS trust regards its employees as its main source of innovation. The trust's commitment to innovation is evident in its support of a whole department dedicated to research and innovation, and in the steps that it has taken to encourage its employees to collaborate with staff in other NHS trusts and academic institutions. In addition, the NHS trust exhibits a strong commitment to champion and implement the ideas generated by its employees.

The informants were recruited using purposive sampling (Barbour, 2001, p. 1115) with the goal of reflecting the views of the workforce population at each site across a range of employee demographics, e.g. age, gender, ethnic background, length of service, and role. Since the purpose of the study was to explore IWB as related to service delivery in general, the university-based participants were restricted to non-academic employees in professional services roles. This is because inclusion of academics in the study would have risked undue attention on innovation specific to teaching practice. The sample of NHS trust participants comprised medical and research practitioners, as well as professional services staff. The total number of participants in each data collection exercise is given in Table II.

Table II: Data collection overview

\begin{tabular}{|c|c|c|c|c|}
\hline \multirow[t]{2}{*}{ Element } & \multicolumn{3}{|c|}{ Participants } & \multirow[b]{2}{*}{ TOTAL } \\
\hline & $\begin{array}{l}\text { Scottish } \\
\text { university }\end{array}$ & Finnish university & $\begin{array}{l}\text { English NHS } \\
\text { trust }\end{array}$ & \\
\hline Interview & 33 & 12 & 12 & 57 \\
\hline $\begin{array}{l}\text { Online } \\
\text { questionnaire }\end{array}$ & 205 & 18 & 104 & 327 \\
\hline Focus groups & $26^{1}$ & $\mathrm{n} / \mathrm{a}$ & $\mathrm{n} / \mathrm{a}$ & 26 \\
\hline $\begin{array}{l}\text { TOTAL PER CASE } \\
\text { STUDY }\end{array}$ & 264 & 30 & 116 & 410 \\
\hline
\end{tabular}

${ }^{1} 6$ focus groups with 3 participants; 2 focus groups with 4 participants. 
Middleton, L. \& Hall, H. (2021, in press). Workplace information literacy: a bridge to the development of Innovative Work Behaviour. Journal of Documentation. (Manuscript accepted for publication 26 ${ }^{\text {th }}$ May 2021.)

The 57 semi-structured interviews were conducted in person on the site of each organisation, and lasted between 30 and 60 minutes each. The eight focus group meetings also took place in the participants' workplace. These lasted between 45 and 75 minutes. The questions in both cases were designed to be open-ended, e.g. 'What part of the culture (values and beliefs of the organisation) help you to develop innovative work behaviour?' In some instances, more specific were posed in the course of an interview or focus group, for example when clarification of a particular answer was required. The thematic content for both the interviews and the focus groups was identical. It comprised two parts. The first encouraged participants to speak about determinants of IWB that are well covered in the extant literature, i.e. those related to (1) organisational culture, strategy, and leadership, and (2) the skills and aptitudes of employees, as summarised above. The second section of the questionnaire related to information behaviours, including IL. Since it was anticipated that the participants would be less familiar with these two terms, simplified definitions of each were offered. The short definition for information behaviours was "how people interact with information'. IL was explained as 'how people recognise when information is needed and the ability to locate, evaluate, and effectively use the information they need'. Presenting these terms in this way provided a straightforward route for the generation of qualitative data about the organisational information landscapes that the participants inhabited, and the nature of their individual and collective information experiences within them.

The online questionnaire was presented to the participants in four sections. The participants were invited to respond to a series of statements in each section using a Likert scale, with the expectation that this task would take no longer than 20 minutes to complete. The first section required participants to rate the importance of factors that contribute to the four stages of the development of IWB noted above, i.e. recognising the need to innovate, creating ideas, championing ideas, and implementing ideas. The factors cited related to the established determinants as summarised above, and to other possible determinants related to information behaviours. In the case of the information-related determinants, the elements offered for rating were informed by established generic models of IL, such as SCONUL's (2011) seven pillars (identify, scope, plan, gather, evaluate, manage, present) and 
Middleton, L. \& Hall, H. (2021, in press). Workplace information literacy: a bridge to the development of Innovative Work Behaviour. Journal of Documentation. (Manuscript accepted for publication 26 ${ }^{\text {th }}$ May 2021.)

CILIP's (n.d.) eight IL competencies (understanding a need for information, the resources available, and means of accessing, evaluating, working with/exploiting, sharing/communicating the information in an ethical and responsible manner). In the second section of the questionnaire, the participants were asked to note their engagement with learning and innovation activities in the 12 months prior to participation in this study. The list of activities presented was adapted from the Workplace Learning Activity Scale (WLA) (see Nikolova, Ruysseveldt, De Witte, \& Syroit, 2014; Fontana, Milligan, Littlejohn \& Margaryan, 2015). The third section of the questionnaire posed two simple questions about access to training and frequency of participation in training. The final section of the questionnaire allowed for the collection of demographic data about the respondents in respect of their education and employment, and their gender, age and ethnicity.

The questionnaire data, and data collected by interview and focus group, were analysed separately for each case study. This was to allow for later comparison of findings. The quantitative data collected in the questionnaires were first analysed using SPSSS v23 in a three-stage process: (1) factor analysis to reduce the number of independent variables into fewer factors for consideration; (2) reliability testing of new factors using Cronbach's alpha and t-tests to determine the significance and direction of trends; and (3) binary logistic regression to explore the factors that predict participation in learning and innovation activities relevant to IWB. Due to the small sample size in the Finnish case study, the binary logistic regressions were only carried out on the quantitative data collected from the Scottish and English case study participants. Thematic data analysis (Guest, MacQueen \& Namey, 2011) was performed on the qualitative data using NVivo v10. In the final stage of the analysis the findings from each case study were brought together to make an assessment of the determinants of the development of IWB, with a particular focus on those that are information-related.

\section{Findings}

\subsection{Findings from the analysis of data collected by questionnaire}

The factors that influence the development of IWB as identified from the analysis of the questionnaire data in each of the three case study organisations are summarised in Table III. 
Middleton, L. \& Hall, H. (2021, in press). Workplace information literacy: a bridge to the development of Innovative Work Behaviour. Journal of Documentation. (Manuscript accepted for publication 26 ${ }^{\text {th }}$ May 2021.)

They are organised into three categories as factors associated with (1) the organisational context in which employees are situated; (2) employee skills and aptitudes, resources and training; and (3) information-related factors.

Table III: Determinants that influence the development of IWB identified from analysis of questionnaire data as identified in the three case study organisations

\begin{tabular}{|c|c|c|c|c|c|}
\hline \multirow[b]{2}{*}{$\begin{array}{l}\text { Determinant } \\
\text { category }\end{array}$} & \multirow[b]{2}{*}{ Determinant } & \multicolumn{4}{|c|}{ Innovative work behaviour stage and case study } \\
\hline & & $\begin{array}{l}\text { Stage 1: } \\
\text { recognise } \\
\text { the need to } \\
\text { innovate }\end{array}$ & $\begin{array}{c}\text { Stage 2: } \\
\text { create idea }\end{array}$ & $\begin{array}{l}\text { Stage 3: } \\
\text { champion } \\
\text { idea }\end{array}$ & $\begin{array}{l}\text { Stage 4: } \\
\text { implement } \\
\quad \text { idea }\end{array}$ \\
\hline \multirow{2}{*}{ 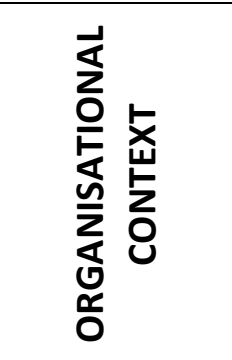 } & Culture & $\begin{array}{l}\text { Scotland } \\
\text { Finland }\end{array}$ & $\begin{array}{l}\text { Scotland } \\
\text { England }\end{array}$ & $\begin{array}{l}\text { Scotland } \\
\text { Finland } \\
\text { England }\end{array}$ & $\begin{array}{l}\text { Scotland } \\
\text { Finland } \\
\text { England }\end{array}$ \\
\hline & Leadership & $\begin{array}{l}\text { Scotland } \\
\text { Finland }\end{array}$ & $\begin{array}{l}\text { Scotland } \\
\text { Finland }\end{array}$ & $\begin{array}{l}\text { Scotland } \\
\text { Finland }\end{array}$ & $\begin{array}{l}\text { Scotland } \\
\text { Finland }\end{array}$ \\
\hline \multirow{3}{*}{ 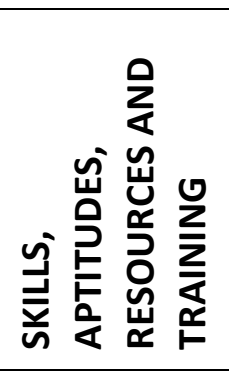 } & $\begin{array}{l}\text { Employee } \\
\text { skills and } \\
\text { aptitudes }\end{array}$ & $\begin{array}{l}\text { Scotland } \\
\text { Finland } \\
\text { England }\end{array}$ & $\begin{array}{l}\text { Finland } \\
\text { England }\end{array}$ & $\begin{array}{l}\text { Scotland } \\
\text { England }\end{array}$ & - \\
\hline & $\begin{array}{l}\text { Access to } \\
\text { resources }\end{array}$ & - & - & Scotland & England \\
\hline & Training & - & $\begin{array}{l}\text { Scotland } \\
\text { England }\end{array}$ & $\begin{array}{l}\text { Scotland } \\
\text { England }\end{array}$ & - \\
\hline \multirow{5}{*}{ 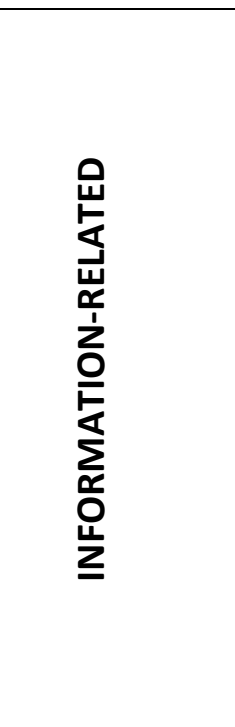 } & IL in general & $\begin{array}{l}\text { Finland } \\
\text { England }\end{array}$ & $\begin{array}{l}\text { Scotland } \\
\text { Finland }\end{array}$ & $\begin{array}{l}\text { Scotland } \\
\text { Finland }\end{array}$ & - \\
\hline & $\begin{array}{l}\text { Recognising } \\
\text { information } \\
\text { needs }\end{array}$ & Scotland & - & Scotland & - \\
\hline & $\begin{array}{l}\text { Locating \& } \\
\text { accessing } \\
\text { information }\end{array}$ & Finland & $\begin{array}{l}\text { Scotland } \\
\text { Finland }\end{array}$ & - & - \\
\hline & $\begin{array}{l}\text { Interpreting \& } \\
\text { analysing } \\
\text { information }\end{array}$ & - & $\begin{array}{l}\text { Scotland } \\
\text { Finland }\end{array}$ & Finland & Finland \\
\hline & $\begin{array}{l}\text { Sharing } \\
\text { information }\end{array}$ & Scotland & $\begin{array}{l}\text { Scotland } \\
\text { Finland } \\
\text { England }\end{array}$ & $\begin{array}{l}\text { Scotland } \\
\text { Finland } \\
\text { England }\end{array}$ & $\begin{array}{l}\text { Scotland } \\
\text { Finland } \\
\text { England }\end{array}$ \\
\hline
\end{tabular}


Middleton, L. \& Hall, H. (2021, in press). Workplace information literacy: a bridge to the development of Innovative Work Behaviour. Journal of Documentation. (Manuscript accepted for publication 26 ${ }^{\text {th }}$ May 2021.)

The presentation of the presence of factors in the case studies against the stages of IWB in this way provides an overview of their relative contribution. It can be seen here, for example, that elements of organisational context were more frequently cited in questionnaire responses across the case study organisations as determinants of IWB than were the other two categories, and that sharing information is the most prominent information-related factor.

Cronbach's alpha tests revealed high internal consistency and reliability of the factors created from the initial independent variables ( $\alpha$ was between .721 and .984 for all factors). When t-tests were performed on the data, the following factors were confirmed as important for IWB to develop in the Scottish and Finnish case study organisations $(p<.001$ for all tests):

- Organisational context: organisational goals and strategy (i.e. elements that contribute to the building or organisational culture, and not leadership)

- Skills, aptitudes, resources and training: personal drive and empowerment, and access to resources (but not training)

- Information-related factors: both IL in general and sharing information

The t-tests for the English case study provided almost identical results. The single difference was that here personal drive and empowerment was not identified as an important factor.

The results of the binary logistic regression tests for the Scottish case study confirmed that following results ( $p<.05$ for all tests):

- Organisational context: organisational goals and strategy (i.e. elements that contribute to the building or organisational culture, and not leadership) helped to work with others to develop new ideas and solutions to problems.

- Skills, aptitudes, resources and training helped people to work alone or with others to create new ideas and solutions to problems, but access to resources and colleagues for advice were important. 
Middleton, L. \& Hall, H. (2021, in press). Workplace information literacy: a bridge to the development of Innovative Work Behaviour. Journal of Documentation. (Manuscript accepted for publication 26 ${ }^{\text {th }}$ May 2021.)

- Information-related factors: sharing information was important to help employees to work together to develop solutions (e.g. create new ideas) to solve problems.

The results of the binary logistic regressions carried out on qualitative data collected from the English case study were similar. However, the difference here was that information sharing also allowed for these NHS employees to follow developments in their field of expertise, and then apply their new knowledge in the creation and implementation of new ideas (e.g. in collaborative work).

The closer alignment of findings between the Scottish and Finnish case study may be an instance of an occupational group (here two sets of professional services staff in higher education) performing as a moderating factor, as noted in the literature review above.

\subsection{Findings from the analysis of data collected by interview and focus group}

The analysis of the interview and focus group data allowed for further exploration of the three categories of factor that influence the development of IWB across its four stages. It should be noted that resources and training, both of which featured in the findings from the analysis of questionnaire data, are not considered separately here. This is because these themes did not emerge strongly in the interviews and focus groups. However, the associated theme of learning - as an output of using resources and participation in training was discussed frequently by the interview and focus group participants. The commentary below thus covers learning with reference to its enabling factors, as identified by the study participants.

\subsubsection{Factors that influence the development of IWB evident from analysis of interview and focus group data: organisational context}

From the analysis of interview and focus group data, two contextual factors are seen to contribute strongly to the development of IWB across all three case studies. These are organisational culture and leadership. It is worth noting here that while the former is 
Middleton, L. \& Hall, H. (2021, in press). Workplace information literacy: a bridge to the development of Innovative Work Behaviour. Journal of Documentation. (Manuscript accepted for publication $26^{\text {th }}$ May 2021.)

prominent in the findings from the analysis of questionnaire data in respect of organisational goals and strategy (as outlined above), the latter is not. Indeed, the findings from the interviews and focus groups on factors of organisational context related to the stages of IWB exhibit a different 'flavour'. This observation is explored in more detail below.

Support for activities related to knowledge sharing and attitudes to risk emerged as the cultural factors most important to the development of IWB. The Finnish participants, for example, emphasised that an organisational culture that is supportive of external networking encourages employees to bring new knowledge into the institution. This can then be deployed in internal knowledge exchange activities, and may lead to the creation of new ideas (stage 2 of IWB). In respect of stage 4 of IWB, open attitudes to risk allow employees to take steps toward the implementation of ideas. For example, the participants in the English NHS trust organisation spoke about this, highlighting that the fear of harming services and patients in healthcare settings can serve as an inhibiting factor in the development of IWB. Even in less risky environments, organisational culture determines the ease with which employees may pass from stage 3 (championing an idea) to stage 4 (implementation). This is illustrated in a comment that Participant 55 (Scotland) made when speaking of efforts to apply new learning for innovation in an unsupportive environment:

I think the culture has to be there for [innovation] to be successful... If you have learned something and you try and implement it, there's a lot of stumbling blocks... If you haven't been able to implement any change or even suggest any change then it sort of defeats the point of learning something new.

The study participants exhibited keen awareness in the interviews and focus groups of the links between organisational culture and strategy. They noted that if these are not tightly aligned in respect of ambitions to innovate, then IWB will not develop effectively within the workforce. This is illustrated in a comment made in one of the focus group discussions when Participant 13 (Scotland) said: ...

Something that we've never really managed as an organisation before is behaviour... What we're doing now is [...] starting to align our objectives to the strategy, and then 
Middleton, L. \& Hall, H. (2021, in press). Workplace information literacy: a bridge to the development of Innovative Work Behaviour. Journal of Documentation. (Manuscript accepted for publication 26 ${ }^{\text {th }}$ May 2021.)

actually starting to measure how we've approached that against the values and behaviours.

Institutional leaders were regarded by the study participants as playing a key role in communicating organisational strategies that focus on innovation. It was advocated in the interview and focus groups that these leaders should promote the development of IWB amongst their staff. This could be achieved by emphasising the organisational drive towards innovation and then striving to garner widespread interest in such efforts. Participant 13 (Scotland) gave a positive example of the outcome of sustained promotion when he/she commented on the evident commitment at senior levels to recent developments in his/her unit:

Within the past couple of years, a new service has been created... The drive behind that service is innovation, resilience... [it comes] not just from the director but from the whole of the management team, in actually creating different ways of working [and] innovation.

Others from the Scottish case study explained that their leaders support stage 3 of IWB when they help colleagues cope with change and fear of failure. For example, Participant 5 (Scotland) said:

It's about how do we support people to be innovative, but also support them when they don't get things quite right. You know there is a bit of a fear around the organisation. I think about 'Oh you know what would happen if you...'

A further comment from the Scottish case study (Participant 38) illustrates the risk of poor leadership in the implementing of ideas stage of IWB:

We are missing stronger sponsorship at senior level to support those changes going through... Some of [the changes] have been pretty significant. The visibility and the voice of the senior team is sometimes missing in these big change projects, and the expectations are high that people will just change, without fully understanding what any impact might be, on individuals, on teams, on the wider organisation.

The analysis of the interview and focus group data also indicated additional tasks of leaders who wish to develop IWB across its four stages. For example, the Finnish participants valued 
Middleton, L. \& Hall, H. (2021, in press). Workplace information literacy: a bridge to the development of Innovative Work Behaviour. Journal of Documentation. (Manuscript accepted for publication 26 ${ }^{\text {th }}$ May 2021.)

their leaders for providing reassurance and support for independent, autonomous idea creation in stage 2.

\subsubsection{Factors that influence the development of IWB evident from the analysis of interview and focus group data: generic employee skills and aptitudes}

The findings from the analysis of interview and focus group data point to the importance of certain generic employee skills and aptitudes in the development of IWB, especially for stages 1 and 2 . As is the case in the findings from the questionnaire responses, a significant aptitude is motivation to learn in the workplace, and then to apply this learning to the creation of new ideas. Participant 63 (England), for example, spoke of the way that such personal drive can influence the IWB of others through championing such behaviour:

I come across health care assistants and nurses [who] are really great at innovating. [They have] that mind-set of 'This is really good and I'm going to encourage other people to do similar'.

However, the most significant skills according to the data analysed from the interviews and focus groups are those that support social interaction. These include communication skills in general, and a willingness to engage in collaborative work, i.e. skills that support information behaviours conducive to information sharing. In IWB stage 2, for example, effective employee communication supports collaboration for the exchange of information and the generation of new ideas. This also ensures that resources are not unintentionally wasted by two units working on similar work without knowledge of one another's activities. For example, Participant 7 (Scotland) explained:

Communication is extremely important. Nobody can work single-handed anymore. It's always a joint effort if you're going to improve work or anything, so open communication in many senses is fundamentally important.

In addition, participants in the English case study pointed out the value of communication to stage 4 of IWB by highlighting the importance of informing employees of support available for the implementation of innovative ideas. 
Middleton, L. \& Hall, H. (2021, in press). Workplace information literacy: a bridge to the development of Innovative Work Behaviour. Journal of Documentation. (Manuscript accepted for publication 26 ${ }^{\text {th }}$ May 2021.)

The ability to reflect was also highlighted during data collection by interview and focus group by participants from the Scottish university. They saw this as a skill that makes it possible for individuals to recognise the need to make a change or innovate (stage 1). It was also argued that reflective employees are also more likely to be able to apply their learning to the creation of new ideas (Stage 2). Participant 4 (Scotland) referred to reflective processes with reference to learning in explaining:

It's a sensible starting point to understand that you need to learn something which is the first bit, so you identify a gap and then find a means of filling it. Sometimes you end up the other way around of course. You can be doing a task and find something you didn't know you didn't know, then you go back and then you reflect on the processes to find the gap.

\subsubsection{Factors that influence the development of IWB evident from analysis of interview and focus group data: information-related}

As might be expected in the light of the findings from the analysis of questionnaire data, a strong message from the analysis of the interview and focus group data is that the development of IWB is dependent on the extent to which the workforce is information literate. This is because IL provides an underpinning for operationalising IWB. The Finnish participants, for example, argued that information literate colleagues have the requisite skills to quickly make sense of any new information made available to them. This speeds up the rate at which employees become aware of any possible future needs for change and are ready to create new ideas to address these, i.e. the first two stages of IWB.

Some specific IL skills were found to be more important than others. First, the ability to recognise information needs was identified in the Scottish and Finnish case studies. Second, effective strategies for gathering information, such as sharing information requests or coping with information overload, were highlighted in all case studies, often with reference to learning. For example, Participant 76 (Finland) said:

I think you [as an employee] have to be very information literate in order to be a good learner in a workplace... This helps to create new ideas. You have to be able to 
Middleton, L. \& Hall, H. (2021, in press). Workplace information literacy: a bridge to the development of Innovative Work Behaviour. Journal of Documentation. (Manuscript accepted for publication 26 ${ }^{\text {th }}$ May 2021.)

recognise what information is relevant for your job: what type of information you need and how you can get at that information.

Similarly, barriers to information gathering caused by the complex nature of institutional information sources was identified in conversation with employees in the Finnish university as detrimental to moving from stage 1 of IWB to stage 2. For example, Participant 74 (Finland) commented:

You sometimes think that 'Oh dear, the information is there.' ... If you don't get the right answer, it doesn't exist, because you don't have the patience to put so much time into finding information.

Common across all case studies was that the view that the ability to interpret and analyse information is key to the initiation of idea creation (stage 2). This is because the recognition of the need to innovate comes through synthesising existing information. Again, the Finnish participants spoke about this with reference to learning processes, identifying that this ability contributes to the assimilation of new knowledge as additional context and meaning is added to information gathered.

It has already been established from the analysis of the questionnaire data that the determinant of sharing information is important to all stages of IWB, and especially to stages 2-4. Similarly, the social nature of information seeking was confirmed when the participants from all three data collection sites noted at interview and in the focus groups that they value co-workers as important information sources. In particular, they drew attention to the convenience of accessing information from others. This is the speed in which such practice can satisfy their information needs, and for the opportunity that it offers to question the meaning of information provided in this way. Participants in the Scottish case study, for example, saw the benefit of this to the idea creation stage of IWB for the opportunity to discuss the feasibility of an idea (stage 2). An employee in the Finnish University (Participant 78) provided the following example at interview:

I also talked about it with our study psychologist, and then we were turning this idea round and looking at it and what could we do? And okay, so she already had some idea that she would. 
Middleton, L. \& Hall, H. (2021, in press). Workplace information literacy: a bridge to the development of Innovative Work Behaviour. Journal of Documentation. (Manuscript accepted for publication 26 ${ }^{\text {th }}$ May 2021.)

Internal information sharing is also valued for championing and implementing ideas (stages 3 and 4 of IWB). In the analysis of interview data from the English case study, for example, it was established that if information shared makes it clear that support is available for employees to implement their ideas within the NHS Trust, then the IWB of employees benefits, particularly in respect of stage 3 .

Sharing information accessed from beyond the home work unit was found from the analysis of interview and focus group data to be important to stage 2 of IWB, especially when employees have engaged in training and learning activities. Participant 4 (Scotland) explained, for example, that when colleagues return from training courses ready to share newly-acquired information with others who work in similar roles elsewhere, this triggers thought processes along the lines of 'Oh, maybe I should do something different'. Participant 82 (Finland) offered a similar example from engaging with external work colleagues:

I use that [newly acquired information from an external colleague] to make a plan or suggestion for an idea, or for the project plan.

\section{Discussion: three categories of factor (not just two) influence the development of IWB}

The findings generated from the questionnaire data presented above confirm that all the determinants of IWB identified in the literature review in section 2.1 are evident in the organisations that furnished the case studies for this research. However, not all of the determinants are relevant in every case. For example, according to the analysis of questionnaire data, leadership does not feature as a factor in the English case study. Similarly, only two determinants (culture and leadership) apply to all stages of IWB. T-tests highlighted the relative importance of organisational goals and strategy within the broad category of factors related to organisational context, and personal drive and empowerment, and access to resources within the broad category of skills, aptitudes, resources and 
Middleton, L. \& Hall, H. (2021, in press). Workplace information literacy: a bridge to the development of Innovative Work Behaviour. Journal of Documentation. (Manuscript accepted for publication 26 ${ }^{\text {th }}$ May 2021.)

training. The determinants are most keenly felt in stages 2 (creation of an idea) and 3 (championing of, and/or gaining support, for the idea).

The analysis of the data from the interviews and focus groups added to the findings from the analysis of questionnaire data. Particular attention is drawn to the significance of the following determinants of IWB in the three case study organisations:

- Knowledge sharing, and an organisational strategy that embraces innovation and change (under culture)

- Leaders who promote IWB, support employees through change, and encourage the development of innovation-related skills through autonomous working (under leadership)

- Employees who are willing to participate in training events and innovation-related activities, and motivated to learn and reflect on such engagement, and develop skills to support social interaction (under skills, aptitudes, resources and training).

The main contribution of the study reported here, however, is to highlight a third category of determinants of IWB and their operationalisation in the workplace, i.e. those that are information-related. Under-reported in the extant literature on determinants of IWB, these are sharing information (which may be related to the established determinant of knowledge sharing under culture as elaborated below), and workplace IL (a new determinant). While information sharing features as an element of IL in many IL models (particularly those that reinforce the 'skills' view of IL, as discussed above), here information sharing is treated as a determinant of IWB in its own right. This is to recognise its prominence in the findings of this study.

In the analysis of the questionnaire data reported above, sharing information is identified in all three case studies as a determinant of the development of IWB across three of its four stages: recognition of the need for innovation (stage 2); creation of an idea (stage 3); and implementation of the idea (stage 4). When compared with all the other determinants, sharing information stands out as the most evident in all three case studies. The only others 
Middleton, L. \& Hall, H. (2021, in press). Workplace information literacy: a bridge to the development of Innovative Work Behaviour. Journal of Documentation. (Manuscript accepted for publication 26 ${ }^{\text {th }}$ May 2021.)

recognised in all the sites in this study are culture in stages 3 and 4, and employee skills and aptitudes in stage 1 . Related to this finding, the analysis of the data collected in interviews and focus groups reveals that the skills considered most important to the development of IWB are those that underpin social interaction, i.e. which support information behaviours conducive to information sharing. This finding fits with the recognition amongst study participants that the most important workplace information sources are other people.

Sharing information has not featured as prominently in prior studies of the determinants of the development of IWB. Rather, it is the related theme of sharing knowledge (i.e. insights, experiences and expertise) that merits attention. However, such discussion is framed within the context of strategies to nurture organisational cultures that are conducive to IWB (e.g. Hu \& Zhao, 2016; Kmieciak, 2020; Radaelli et al, 2014) rather than information behaviours, and while accepted as a determinant of IWB, sharing knowledge is not elaborated any further (e.g. Akhaven et al, 2015).

Also unique in this study are findings on the organisational value of workplace IL to the development of IWB. Workplace IL has been found to be particularly important in respect of the workplace learning required for creating and championing ideas (stages 2 and 3 of IWB). With reference to learning more generally, the study participants indicated that an information literate workforce is able to assimilate and apply new knowledge more quickly than one that is not. This notion that information literate workforce members can navigate the workplace information landscape to develop knowledge and skills for successful work performance resonates with the work of Lloyd, echoing the claim that 'Without information literacy, other work-related practices and performances couldn't be accomplished' (2011, p. 277). In the case studies examined for this study, IL appears to furnish a bridge between well-known determinants of the development of IWB (i.e. those related to organisational context, and to skills, aptitudes, resources and training) and workplace learning. It helps employees identify gaps in their knowledge, and recognise and set about meeting their information needs. 
Middleton, L. \& Hall, H. (2021, in press). Workplace information literacy: a bridge to the development of Innovative Work Behaviour. Journal of Documentation. (Manuscript accepted for publication 26 ${ }^{\text {th }}$ May 2021.)

Given the strong messages from the three case study sites, it is rather curious that these information-related factors have not previously been identified as determinants of the development of IWB. This merits some consideration to forward possible explanations for the 'discovery' here of these 'new' determinants. Three reasons for this can be forwarded.

The first explanation relates simply to vocabulary use. While Information Scientists take care to distinguish the terms 'information' and 'knowledge' in their research, others are less discriminating, often deploying the terms interchangeably. Thus, in prior work on IWB undertaken by researchers outside Information Science, the concept of 'information sharing' may be assumed in the use of the term 'knowledge sharing' in published accounts of their research. Further research is needed to confirm or refute this, especially taking into account that knowledge sharing is considered an aspect of culture in prior research on determinants of IWB, as opposed to a facet of information behaviour in general, or a stage in IL.

The second possible reason for the lack of acknowledgement of IL might be that all workers are anticipated to be information literate, mirroring the expectation that they can read and write, and are already numerate, before entering the workforce. To argue that general literacy is a fundamental determinant of the development of IWB is uncontentious, and so obvious that general literacy is clearly not a factor of influence worthy of research attention. This argument is less convincing, however, when applied to IL, especially since the term is not commonplace beyond the realms of Library and Information Science.

A further explanation for the novelty of these findings is that research on workplace IL is most often concerned with the learning of IL skills rather than the use of IL in the support of wider organisational capabilities such as workplace learning. The reason that informationrelated determinants of the development of IWB came to the fore in this work is that this study - unlike those that privilege the learning of IL skills - was designed to look for them.

This deliberate activity, prompted by considerations of the possible interplay between workplace IL and workplace learning as applied to the development of IWB, may be 
Middleton, L. \& Hall, H. (2021, in press). Workplace information literacy: a bridge to the development of Innovative Work Behaviour. Journal of Documentation. (Manuscript accepted for publication 26 ${ }^{\text {th }}$ May 2021.)

considered a strength of the research reported here. However, this work shares a limitation common to studies that concern IL: reliance on reports of study participants who are not experts in the domain of the research (Widén et al, 2021 in press). Here the participants provided questionnaire responses and contributions in interviews and focus groups that, when analysed, have allowed for an exploration of possible information-related determinants of IWB. Insights into the impact of information sharing and workplace IL introduced in this work merit further scrutiny to build on this initial identification of a third category of IWB determinants. In any future work it would also be advisable to achieve a more even balance across case study data sets than was the case here (see Table 2).

The value of the research findings presented here also risk the limitations of all work in which several somewhat porous determinants are examined across a rather artificially defined set of processes. Just as Woods et al. (2018, p. 31) note that the effects of personality on the development IWB may not be justified because the scope of personality is wide-ranging and the effects of personality may interact with other personal and contextual variables, there are indications here that the influence of determinants identified in this study are context-dependent. Note, for example, the alignment of findings in the analysis of questionnaire data from the two higher education institutions in the study. It would be useful, for example, to use the same research design in a study of the determinants of IWB in three companies to determine whether not these 'new' information-related determinants are relevant in a corporate environment, i.e. beyond the public sector.

Notwithstanding these limitations, the findings of this research point to two recommendations for employers keen to develop IWB within their workforces. The first is to make provision for the enhancement of workplace IL. In terms of formal training, this should include coverage of the two key themes: information overload (e.g. how to deal with it/avoid contributing to it); navigating organisational information sources/making organisational information sources navigable for colleagues. Secondly, employers need to value the knowledge of employees and provide for its exploitation, appreciating that workplace IL derives from the social and informal ways in which information is transformed 
Middleton, L. \& Hall, H. (2021, in press). Workplace information literacy: a bridge to the development of Innovative Work Behaviour. Journal of Documentation. (Manuscript accepted for publication 26 ${ }^{\text {th }}$ May 2021.)

into knowledge (Williams et al., 2014, pp. 2-3). This could be achieved, for example, through the creation of internal networks and the support of communities of practice. These recommendations relate to the theme of empowerment, as previously identified in the broader IWB literature (Bos-Nehles et al, 2017, p. 1240).

\section{Conclusion}

In a recent review of the literature on IWB, it was noted that knowledge of IWB and its determinants is scattered and sometimes contradictory (Bos-Nehles et al, 2017). The research presented here has also revealed that knowledge of IWB is also incomplete. This has been made evident by highlighting a third broad category of IWB determinants in addition to those related to organisational context and, to skills and aptitudes of employees. These are information-related determinants, namely information sharing and workplace IL. In the case of the latter, and using the vocabulary of the Theory of information literacy cited above (Lloyd, 2017, p. 94), workplace IL here is a 'way of knowing' how to use information to develop IWB.

As such, this work makes a novel contribution to the body of work on IWB, while also adding to a decade and a half of IL research that explores the extent to which IL supports workplace learning development (e.g. Lloyd, 2010; Lloyd 2012; Lloyd \& Somerville, 2006). This consideration of workplace IL as a practice that contributes to the 'performance' of IWB through the application of information-related skills and activities across three public sector organisational settings widens the discussion of information behaviours in general and innovation in general at work. It also highlights that information professionals should consider the ways in which they might contribute to supporting the information-related determinants of IWB in their own workplaces. The firm evidence that information-related determinants are important to the development of IWB suggests that it is time for researchers and professionals beyond the domain of Information Science to pay serious attention to IL. 
Middleton, L. \& Hall, H. (2021, in press). Workplace information literacy: a bridge to the development of Innovative Work Behaviour. Journal of Documentation. (Manuscript accepted for publication $26^{\text {th }}$ May 2021.)

\section{Acknowledgements}

The empirical research reported in this paper was funded by a Collaborative PhD studentship awarded by the UK Economic and Social Research Council (ESRC) and Skills Development Scotland (SDS), (grant number: ES/J500136/1). The authors thank all who participated in the empirical study. In addition, they acknowledge their former Edinburgh Napier University colleagues Dr Robert Raeside and Dr Laura Muir, who co-supervised the PhD alongside Dr Hazel Hall as Director of Studies. The authors are also grateful to Dr David Brazier, Dr Peter Cruickshank, Marina Milosheva, and Dr Gunilla Widén, who generously contributed valuable comments on an early draft of the paper.

\section{References}

Ahmad, F., Widén, G., \& Huvila, I. (2020). The impact of workplace information literacy on organizational innovation: an empirical study. International Journal of Information Management, 51, 1-15.

Akhavan, P., Mahdi Hosseini, S., Abbasi, M. \& Nateghi, M. (2015). Knowledge-sharing determinants, behaviors, and innovative work behaviors: an integrated theoretical view and empirical examination. Aslib Journal of Information Management, 67(5), 562-591.

Alasoini, T. (2015). Two decades of programme based promotion of workplace innovation in Finland: past experiences and future challenges. European Journal of Workplace Innovation, 1(1), 37-54.

Åmo, B.W. \& Kolvereid, L. (2005). Organizational strategy, individual personality and innovation behaviour. Journal of Enterprising Culture, 13, 7-19.

Anderson, N., de Dreu, C. K. W., \& Nijstad, B. A. (2004). The routinization of innovation research: a constructively critical review of the state-of-the-science. Journal of Organizational Behavior, 25, 147-173.

Andersson, S. B. (2006). Newly qualified teachers' learning related to their use of information and communication technology: A Swedish perspective. British Journal of Educational Technology, 37(5), 665-682.

Auernhammer, J., \& Hall, H. (2014). Organizational culture in knowledge creation, creativity and innovation: towards the Freiraum model. Journal of Information Science, 40(2), 154166

Bakker, A.B. \& Demerouti, E. (2007). The job demands-resources model: state of the art. Journal of Managerial Psychology 22(3), 309-328.

Barbour, R.S. (2001). Checklists for improving rigor in quantitative research: a case of the tail wagging the dog? British Medical Journal, 322(7294), 1115-1117.

Battistelli, A., Montani, F., \& Odoardi, C. (2013). The impact of feedback from job and task 
Middleton, L. \& Hall, H. (2021, in press). Workplace information literacy: a bridge to the development of Innovative Work Behaviour. Journal of Documentation. (Manuscript accepted for publication $26^{\text {th }}$ May 2021.)

autonomy in the relationship between dispositional resistance to change and innovative work behaviour. European Journal of Work and Organizational Psychology, 22(1), 26-41.

Billett, S. (2012). Workplace Learning. In N.M. Steel (Ed.), Encyclopaedia of the sciences of Bocklearning (pp. 3446-3483). New York: Springer.

Blau, P.M. (1964). Exchange and power in social life. Wiley, New York, NY.

Bos-Nehles, A., Renkema, M. \& Janssen, M. (2017). HRM and innovative work behaviour: a systematic literature review. Personnel Review, 46(7), 1228-1253.

Botha, L., \& Steyn, R. (2020). Psychological contract breach and innovative work behaviour: Systematic literature review. The Southern African Journal of Entrepreneurship and Small Business Management, 12(1), 1-8.

Cheuk. B. (2008). Delivering business value through information literacy in the workplace. Libri, 58(3), 137-143.

Cheuk, B. (2017). The hidden value of information literacy in the workplace context: how to unlock and create value. In M. Forster (Ed.), Information literacy in the workplace (pp. 131-148). London, United Kingdom: Facet.

CILIP (n.d.). Definitions and models. Available at https://infolit.org.uk/definitions-models/ $\left(14^{\text {th }}\right.$ March 2021).

Clarke, N. (2005). Workplace learning environment and its relationship with learning outcomes in healthcare organisations. Human Resource Development International, 8(2), 185-205.

Cruickshank, P., Hall, H. \& Ryan, B. (2020). Information literacy as a joint competence shaped by everyday life and workplace roles amongst Scottish community councillors. Information Research, 25(4).

De Jong, J. \& Den Hartog, D. (2010). Measuring innovative work behaviour. Creativity and Innovation Management 19(1), 23-36

De Spiegelaere, S., van Guys, G., \& van Hootegem, G. (2012). Job design and innovative work behaviour: one size does not fit all types of employees. Journal of Entrepreneurship, Management and Innovation 8(4), 5-20.

Deci, E.L. \& Ryan, R.M. (1985). Intrinsic motivation and self-determination in human behaviour. Springer: New York.

Ellström, P.E (2010). Practice-based innovation: A learning perspective. Journal of Workplace Learning, 22(1/2), 27-40.

Eriksson, T., Qin, Z \& Wang, W. (2014). Firm-level innovation activity, employee turnover and HRM practices - Evidence from Chinese firms. China Economic Review. 30(C), 583597.

Ferincz, A., Hortoványi, L. (2014). Beyond human-computer collaboration: supporting and hindering factors of on-the-job learning. An Enterprise Oddysey, 847-868.

Fernandez, S. \& Moldogaziev, T. (2013). Employee empowerment, employee attitudes, and performance: testing a causal model. Public Administration Review 73(3), 490-506. 
Middleton, L. \& Hall, H. (2021, in press). Workplace information literacy: a bridge to the development of Innovative Work Behaviour. Journal of Documentation. (Manuscript accepted for publication 26 ${ }^{\text {th }}$ May 2021.)

Fontana, R.P., Milligan, C., Littlejohn, A., \& Margaryan, A. (2015). Measuring self-regulated learning in the workplace. Training and Development, 19(1), 32-52.

Forster, M. (2017). Information literacy and the workplace: new concepts, new perspectives? In M. Forster (Ed.), Information literacy in the workplace (pp. 1-9). Facet.

Gagné, M. \& Deci, E.L. (2005). Self-determination theory and work motivation. Journal of Organizational Behavior 26(4), 331-362.

Goldstein, S. \& Whitworth, A. (2017). Determining the value of information literacy for employers. In M. Forster (Ed.), Information literacy in the workplace (pp. 67-84). Facet.

Guest, G., MacQueen, K. M., \& Namey, E. E. (2011). Applied thematic analysis. Thousand Oaks, CA: Sage.

Gustavsson, M. (2009). Facilitating expansive learning in a public sector organization. Studies in Continuing Education, 31(3), 245-259.

Hamel G. (2007). The future of management. Cambridge: Harvard Business School Press.

Høyrup, S. (2010). Employee-driven innovation and workplace learning: basic concepts, approaches and themes. Transfer: European Review of Labour and Research, 16(2), 143-154.

Hu, B., and Zhao, Y. (2016), Creative self-efficacy mediates the relationship between knowledge sharing and employee innovation. Social Behavior and Personality 44(5), 815826.

Janssen, O. (2000). Job demands, perceptions of effort-reward fairness and innovative work behaviour. Journal of Occupational and Organizational Psychology, 73(3), 287-302.

Janssen, O. (2005). The joint impact of perceived influence and supervisor supportiveness on employee innovative behaviour. Journal of Occupational and Organizational Psychology, 78(4), 573-578.

Jung, D. I., Chow, C., \& Wu, A. (2003). The role of transformational leadership in enhancing organizational innovation: Hypotheses and some preliminary findings. Leadership Quarterly, 14(4-5), 525-544.

Liao, S., Wu, C., Hu, D \& Tsui, K. (2010). Relationships between knowledge acquisition, absorptive capacity and innovation capability: an empirical study on Taiwan's financial and manufacturing industries. Journal of Information Science, 36(1), 19-35.

Kmieciak, R. (2020). Trust, knowledge sharing, and innovative work behavior: empirical evidence from Poland. European Journal of Innovation Management. Online first: https://doi.org/10.1108/EJIM-04-2020-0134

Knol, J., \& van Linge, R. (2009). Innovative Behaviour. The Effect of Structural and Psychological Empowerment on Nurses. Journal of Advanced Nursing, 65(2), 359-370.

Koloniari, M., Vraimaki, E. \& Fassoulis, K. (2018). Fostering innovation in academic libraries through knowledge creation. Journal of Academic Librarianship, 44(6), 793-804.

Krause, D.E. (2004) Influence-based leadership as a determinant of the inclination to innovate and of innovation-related behaviors: an empirical investigation. Leadership Quarterly, 15, 79-102. 
Middleton, L. \& Hall, H. (2021, in press). Workplace information literacy: a bridge to the development of Innovative Work Behaviour. Journal of Documentation. (Manuscript accepted for publication $26^{\text {th }}$ May 2021.)

Lavranos, C., Kostagiolas, P.A., Martzoukou, K., \& Papadatos, J. (2015). Music information seeking behaviour as motivator for musical creativity: Conceptual analysis and literature review. Journal of Documentation, 71(5), 1070-1093.

Lievens, F., Chasteen, C.S., Day, E.A. \& Christiansen, N.D. (2006). Large-scale investigation of the role of trait activation theory for understanding assessment center convergent and discriminant validity. Journal of Applied Psychology, 91(2), 247-258.

Lloyd, A. (2010). Information literacy landscapes: information literacy in education, workplace and everyday context. Chandos: London.

Lloyd, A. (2011). Trapped between a rock and a hard place: what counts as information literacy in the workplace and how is it conceptualized? Library Trends, 60(2), 277-296.

Lloyd, A. (2012). Information as a socially enacted practice: sensitising themes for an emerging perspective of people-in-practice. Journal of Documentation, 68(6), 772-783.

Lloyd, A. (2017). Information literacy and literacies of information: a mid-range theory and model. Journal of Information Literacy, 11(1), 91-105.

Lloyd, A., \& Somerville, M. (2006). Working information. Journal of Workplace Learning, 18(3), 186-198.

Lundkvist, A. H. \& Gustavsson, M. (2018). Conditions for employee learning and innovation interweaving competence development activities provided by a workplace development programme with everyday work activities in SMEs. Vocations in Learning, 11(1), 45-63.

Martins, E., \& Martins, N. (2002). An organisational culture model to promote creativity and innovation. SA Journal of Industry Psychology, 28(4), 58-65.

Martins, E. C., \& Terblanche, F. (2003). Building organisational culture that stimulates creativity and innovation. European Journal of Innovation Management, 6(1), 64-74.

Messmann, G., \& Mulder, R. H. (2011). Innovative work behaviour in vocational colleges: understanding how and why innovations are developed. Vocations and Learning , 4(1), 63-84.

Middleton, L., Hall, H., Muir, L. \& Raeside, R. (2019). The interaction between people, information and innovation: information literacy to underpin innovative work behaviour in a Finnish organisation. In: Proceedings of the 81st Annual Meeting of the Association for Information Science and Technology, 55(1).

Muchiri, M.K., McMurray, A.J., Nkhoma, M. \& Pham, H.C. (2020). Mapping antecedents of innovative work behaviour: a conceptual review. Journal of Developing Areas 54(4), 3340.

Mumford, M. D., Scott, G. M., Gaddis, B., \& Strange, J. M. (2002). Leading creative people: Orchestrating expertise and relationships. Leadership Quarterly, 13(6), 705-750.

Nikolova, I., Van Ruysseveldt, J., De Witte, H., \& Syroit, J. (2014). Work-based learning: Development and validation of a scale measuring the learning potential of the workplace (LPW). Journal of Vocational Behaviour, 84(1), 1-10.

Noefer, K., Stegmaier, R., Molter, B., \& Sonntag, K. (2009). Great many things to do and not a minute to spare: can feedback from supervisors moderate the relationship between 
Middleton, L. \& Hall, H. (2021, in press). Workplace information literacy: a bridge to the development of Innovative Work Behaviour. Journal of Documentation. (Manuscript accepted for publication $26^{\text {th }}$ May 2021.)

skill variety, time pressure and employees' innovative behavior? Creativity Research Journal, 21(4), 284-293.

Oksanen, K., \& Ståhle, P. (2013). Physical environment as a source for innovation: investigating the attributes of innovative space. Journal of Knowledge Management, $17(6), 815-827$.

Olsson, M.R. (2014). Information practices in contemporary cosmopolitan civil society. Cosmopolitan Civil Societies Journal, 6(2), 79-93.

Popoola, S. O., \& Fagbola, O. O. (2014). Innovation capability of managers in Nigerian largescale manufacturing companies. South African Journal of Information Management, 16(1). e1-e10.

Prajogo, D. I. (2016). The strategic fit between innovation strategies and business environment in delivering business performance. International Journal of Production Economics, 171, 241-249.

Pratoom, K., \& Savatsomboon, G. (2010). Explaining factors affecting individual innovation: The case of producer group members in Thailand. Asia Pacific Journal of Management, 29(4), 1063-1087.

Radaelli, G., Lettieri, E., Mura, M. \& Spiller, N. (2014). Knowledge sharing and innovative work behaviour in healthcare: a micro-level investigation of direct and indirect effects. Creativity and Innovation Management, 23(4), 400-414

Ramamoorthy, N., Flood, P.C., Slattery, T. \& Sardessai, R. (2005). Determinants of innovative work behaviour: development and test of an integrated model. Creativity and Innovation Management, 14(2), 142-150.

Ravenscroft, A., Schmidt, A., Cook, J., \& Bradley, C. (2012). Designing social media for informal learning and knowledge maturing in the digital workplace. Journal of Computer Assisted Learning, 28(3), 235-249.

Rude, D. A. (2014). New leader agendas and legacy organizational culture : a case study exploring learning's role in bridging the great divide. American Journal of Management, 14(1-2), 82-102.

Sarros, J. C., Cooper, B. K., \& Santora, J. C. (2008). Through Transformational Leadership and Organizational Culture. Journal of Leadership \& Organizational Studies, 15(2), 145-158.

SCONUL (2011). The SCONUL seven pillars of information literacy. Available https://www.sconul.ac.uk/sites/default/files/documents/coremodel.pdf (14 ${ }^{\text {th }}$ March 2021).

Scott, S.G. \& Bruce, R.A. (1994). Determinants of innovative behaviour: a path model of individual innovation in the workplace. Academy of Management Review, 37(3), 580-607.

Shanker, R., Bhanugopan, R., Heijden, B. I. J. M. Van Der, \& Farrell, M. (2017). Organizational climate for innovation and organizational performance : The mediating effect of innovative work behavior. Journal of Vocational Behavior, 100, 67-77.

Somerville, M.M., Bruce, C.S. (2017). From transaction to transformation: organizational learning and knowledge creation experience within Informed Systems. In: Forster, M. 
Middleton, L. \& Hall, H. (2021, in press). Workplace information literacy: a bridge to the development of Innovative Work Behaviour. Journal of Documentation. (Manuscript accepted for publication $26^{\text {th }}$ May 2021.)

(Ed.) Information literacy in the workplace, pp. 41-55. London: Facet.

Todd. 2017. Information literacy: agendas for a sustainable future. Journal of Information Literacy, 11(1), 120-136.

Webber, S. \& Johnston, B. (2017). Information literacy: conceptions, context and the formation of a discipline. Journal of Information Literacy, 11(1), 156-183.

West, M. A., \& Farr, J. L. (1990). Innovation and creativity at work: Psychological and Organizational Strategies. NY: John Wiley \& Sons.

Widén, G., Ahmad, F., Nikou, S., Ryan, B. \& Cruickshank, P. (2021 in press). Workplace information literacy: measures and methodological challenges. Journal of Information Literacy 15(2).

Williams, D., Cooper, K., \& Wavell, C. (2014). Information literacy in the workplace: an annotated bibliography. Aberdeen: Robert Gordon University. Retrieved from https://www.informall.org.uk/wp-content/uploads/2015/11/Workplace-IL-annotatedbibliography.pdf (14 ${ }^{\text {th }}$ March 2021)

Woods, S. A., Mustafa, M. J., Anderson, N., \& Sayer, B. (2018). Innovative work behavior and personality traits. Journal of Managerial Psychology, 33(1), 29-42.

Zurkowski, P. (1974). The information services environment: relationships and priorities. Report No. NCLIS-NPLIS-5, November, 1974, Washington: National Commission on Libraries and Information Science. Retrieved from:

http://files.eric.ed.gov/fulltext/ED100391.pdf (14 ${ }^{\text {th }}$ March 2021) 